\title{
NON-AGENDA
}

With the view of causing an increase to take place in the mass of national wealth, or with a view to increase of the means either of subsistence or enjoyment, without some special reason, the general rule is, that nothing ought to be done or attempted by government. The motto, or watchword of government, on these occasions, ought to be - Be quiet...Whatever measures, therefore, cannot be justified as exceptions to that rule, may be considered as non-agenda on the part of government.

- Jeremy Bentham (c.1801)

\section{A Charitable Concern}

\section{Gabrielle Berman}

7 he role of information within the charitable sector poses all the dilemmas faced by economists in dealing with imperfect markets. Lack of price signals and asymmetric information imply that decision making at the individual level is likely to be less transparent than in many other sectors, and at the policy level may be largely misinformed. The regulation of this sector is predominantly the domain of state legislation. The introduction of the Victorian Fund raising Appeals Act 1998 and other legislation is argued to be enacted on the premise that it will ensure greater accountability to the donating public by imposing greater reporting requirements. This article examines the efficacy, scope and limitations of information disclosure requirements in current legislation governing the charitable community.

In this paper accountability will be defined using The Australian Concise Oxford Dictionary definition of accountability; that is, to 'give a reckoning of or answer for (money etc. entrusted).' The argument for greater financial accountability in the sector perhaps may be best advocated on the grounds of perceived needs. Funders and donors seem to be demanding greater financial accountability of these organisations. If these claims are valid, the establishment of these systems may be seen as a means to reduce accountability concerns and address expectations held by funders. These expectations are highlighted in donor surveys, (O'Keefe and Partners, 1998; IOOF and ASSIRT, 1998; Campbell, 1998) and are expressed as uncertainty with respect to the use of donational finances for

Gabrielle Berman is a PhD Student in the School of Economics and Finance, Royal Melbourne Institute of Technology. 
stated purposes. More simply put, these surveys suggest that donors are concerned about the proportion and effectiveness of funds donated going directly towards the programs advertised. Through an examination of current financial reporting requirements as well as potential changes to these requirements, an analysis may be conducted to determine possible impacts on reducing or alleviating accountability concerns in the sector.

Hence, this paper will consider public disclosure of financial information by charities to account for moneys received. This definition becomes problematic if one considers the myriad of stakeholders for whom a charity may be accountable to for moneys received. The list of these stakeholders is extensive, ranging from government departments to debtors to individual donors and the general public. For simplification purposes however, we will limit the analysis to financial accountability of charities for household monetary donations.

\section{The Current Legislation}

Charities may take on the form of an unincorporated association (estimates based on local council data indicate that there could have been over three hundred and eighty thousand of these organisations in 1995 (Pocklington et al, 1995)), an incorporated association (as at June 30 1996, over one hundred and four thousand non-trading organisations in Australia were registered as incorporated associations (Huntly, 1996)) or a company limited by guarantee. Other charities are legislated by their own Act of Parliament or by Royal Charter. The basic reporting requirements of these associations are determined by the form of association. These requirements range from audited financial statements presented to parliament to informal financial statements provided to committee members only. It is important to note that while some of these organisations are not compelled under legis!ation to produce full financial details in annual reports, they may do so anyway.

An examination of the various Acts that govern charities facilitates an appreciation of the legislative environment under which they operate as well as providing a starting point from which to assess the effectiveness of current, externally imposed, financial accountability systems.

\section{Issues of State Based Legislation}

An analysis of current legislation highlights inconsistencies in the definition and regulation of charities. There is little consistency across states, and within each state, the various forms of association (Unincorporated Association, Incorporated Association, Company Limited by Guarantee, Royal Charter, Own Act) determine the form of regulation. This disparity may also occur within an organisation if it has several offices in several states. In these instances it is common to create a central company limited by guarantee that will preside over independent incorporated associations regulated by their respective state legislation (Fitzgerald, 1997). The company limited by guarantee is the only organisational form whose 
legislation is consistent across the states. This consistency is primarily the result of a Commonwealth as opposed to State, regulatory body, in the form of the Australian Securities and Investments Commission. This uniformity in legislation however, has not effectively resulted in uniformity in regulation and reporting requirements of charitable companies. Companies limited by guarantee under $\mathbf{s 6 6}$ of the Companies Code that were granted exemption from lodging annual accounts with the Australian Securities Commission prior to 1986 remain exempt under $\mathbf{1 5 0}$ of the Corporations Law.

The fund raising legislation also suffers similar deficiencies. The disparity in the reporting requirements for each of the states, and the absence of any regulation in the Northern Territory and Tasmania effectively implies that the degree of regulation of fund raising is highly contingent on the state in which an association is incorporated. Furthermore, in the Australian Capital Territory (ACT), South Australia (SA) and Western Australia (WA) the fund raising legislation has not been substantially altered since 1959,1939 and 1946 respectively, resulting in the imposition of less rigorous reporting requirements for these states. This is further compounded by the differing exemptions in each state. New South Wales and Victoria effectively exempt religious charities from many of the reporting requirements in their respective statutes.

\section{Heterogeneity Issues in Financial Reporting Requirements}

The dilemma that this lack of homogeneity in reporting requirements poses is twofold. Firstly, heterogeneity in reporting requirements results in a lack of financial comparability between different organisations and, secondly, it encourages the evolution of somewhat esoteric reporting statements. One may argue that given the diversity and intangible nature of the services provided by charities, this situation is a product of the character of the sector, rather than deficiencies in the legislation. It has however, been proffered that the idiosyncratic approach to accounting and financial reporting evident in the not-forprofit sector may be more attributable to historical accident than to the eclectic financial accountability and management requirements of the sector (Perrin, 1985). The validity of these arguments remains purely academic if public perception holds that comparability and transparency in financial reporting can and does engender greater trust. If this is in fact the case, then it is probable that the current legislation is inadequate to foster this trust.

An analysis of the various reporting requirements for each state reveals few control mechanisms for assessing the validity of the figures contained in the financial reports. Aside from those charities that are Limited by Guarantee (and not exempted under s150 of the Corporations Law), it is only those incorporated associations in the ACT and Victoria (that have gross receipts in excess of $\$ 500,000$ and $\$ 200,000$ per annum respectively) that are required by law to have financial reports in compliance with generally accepted accounting standards. The implications for the states and organisations that are not required to adhere to 
these standards is that the information contained within their financial statements is to some degree ad hoc, non-comparable and most certainly esoteric.

The issue of verifiability must also be considered when examining limitations

to current legislation. Mandatory annual audits of financial statements are imposed only on the following; Companies Limited by Guarantee (again excluding exempted companies), those incorporated associations in the ACT, Victoria and SA that generate gross revenue in excess of $\$ 150,000$ and $\$ 200,000$ per annum respectively, as well as incorporated associations in Tasmania and the Northern Territory.

\section{Heterogeneity Issues in Other Disclosure Requirements}

The deficiencies that are present in the legislation do not merely pertain to reporting requirements. Charities in Victoria and NSW alone are required by law to disclose information regarding payments to canvassers or collectors. The issue of disclosure of use of funds has particular relevance in regard to paid collectors. The payment of these collectors is the most immediate indication for donors of funding not going to the final recipients. The requirement for paid canvassers to display a badge or give a verbal indication that they are being paid, at the outset, reduces this particular information asymmetry. The presumption that this information will be factored into the donor decision making process is not unreasonable and may lead to more informed and efficient allocation of monetary donations. The advantage of this type of disclosure is that it allows donors to convey to charities their attitudes towards charities use of funds. Organisations may find that the public responds poorly to paid collectors and may have to look to recruiting volunteers for these purposes. Alternatively, despite the surveys to the contrary (IOOF and ASSIRT, 1997; O'Keefe \& Partners, 1998; Campbell, 1998) many charities may find that donors are, in reality, indifferent to the proportion of funding that gets to the final recipient and continue to donate despite this disclosure. The public response to this information would give charities a far better understanding of donors' true preferences with respect to proportional funding to final recipients than that produced by current surveys.

A further concern in the current fund raising legislation is the lack of specific regulations dealing with the labelling, handling and reporting of money and goods collected in the various receptacles. Only Victoria and NSW have specific requirements outlining the collection and reporting of monies received and expended in the course of collections from clothing bins. Additionally, Victoria and NSW are the only two states that require proper supervision of the use and emptying of collection receptacles. The lack of legislation in this area in the other states may not be problematic if donors are indifferent to the utilisation of these resources. It may be argued that the disposal of clothing is providing a service in and of itself, regardless of the use. Under these circumstances there still remains an argument in favour of regulation if the enforcement of systems to monitor and record the collection reassures donors and is capable of instilling a greater degree of trust. This assumption would necessarily extend to the reporting requirements 
for fund raising appeals that exist in NSW, Queensland and Victoria. The mere certainty of access to this information (whether exercised or not) may do much to dispel fears that monies are being disposed of contrary to donor expectations.

\section{Their Own Act: Religious Entities and Other Organisations}

Many of the larger Australian religious orders have adopted a legal identity through the establishment of their own Act of Parliament (Church). The Salvation Army (Southern and Eastern Commands), Wesley Mission Sydney, The Anglican Home Mission Society and The Brotherhood of St. Laurence are some of the larger religious charities covered by their own Act or affiliated with a church that has its own Act. The Anti-Cancer Council of Victoria and the Royal NSW Institute for Deaf and Blind Children similarly have their own Acts of Parliament. It is significant to note that these organisations formed close to 25 per cent of Australia's largest revenue generating community service welfare organisations in 1993-94 (Industry Commission, 1995). More specifically, four out of the ten top revenue generators were in fact incorporated by their own Act of Parliament (Church). It becomes apparent that these religious associations play a central role in the provision of welfare service, and can and do generate revenues from donations, government support or services charges to the order of millions of dollars per annum (Industry Commission, 1995). The degree of regulation of these associations, the reporting requirements and the required forms of disclosure are determined by the organisation's Act, and the boundaries of incorporation.

Given the significance and the size of many of these organisations there may be a legitimate concern in current regulation. Their sheer size and revenue base suggests that they may have more in common with medium-to-large size corporations than the smaller, community based charities. They are responsible for the effective management of substantial cash flows and sizeable asset holdings (Industry Commission, 1995). Similarly sized profit and non-profit companies have definitive, homogeneous and thus comparable reporting requirements and must submit audited returns to an external independent body. Those organisations incorporated under their own Act may be required under their Act to submit audited financial statements to an independent, external body (usually parliament) however, this is not necessarily the case for religious organisations. These entities are either completely incorporated under their Act of Parliament (church) with self determined external reporting requirements (the degree of which is largely determined by the year of the enactment), or unincorporated organisations (with no specific legal identity and thus no external regulation) that have merely established a Charitable Property Trust under the Act.

\section{Religious Organisations and Concerns Over Current Legislation}

A close examination of the legislation reveals that some of the larger and older religious institutions have not had their Acts substantially revised since their enactment. The concern raised here is that the wave of reforms over the last few 
decades with their emphasis on more rigorous financial disclosure and auditing requirements may not be reflected in these Acts.

Thus, it may be argued that any concerns regarding the financial accountability of organisations that are incorporated under their own Act may not find reassurance in the legislation. The fund raising legislation does little to compensate. Religious organisations (defined as those enumerated under s26 of the Marriage Act 1961) are exempt from many of the reporting requirements imposed by the fund raising legislation in Victoria, NSW and Queensland. Given that these three states have the most rigorous reporting requirements in Australia, there seems to be minimal regulation of fundraising, and few reporting requirements for those religious organisations that are incorporated under their own Act.

\section{Slipping Through the Safety Net}

It is interesting to note that the decision to exempt certain organisations (including Religious Organisations) under the Victorian Fund raising Appeals Act 1998 was premised on pre-existing legislation, that is, they were seen to be regulated under alternative legislation. The exemptions were granted on the grounds that they would be unnecessarily burdened, and the imposition of the Act would imply that there would be duplication in reporting requirements. The validity of this claim for religious charities is not obvious. Given that each religious order has a separate Act, and that many of the larger religious organisations have not substantially revised their Acts for several decades (e.g., Act to Provide for the Temporal Affairs of the Salvation Army in the State of Victoria 1930, Anglican Church of Australia Constitution 1960) it follows that many do not, in fact, have any rigorous external reporting requirements in their own legislation in the first instance, and hence it is probable that the imposition of the Fund raising Appeals Act would not necessarily result in substantial duplication.

Further to this, an analysis of the Second Reading Speeches for the Fund raising Appeals Bill (Victorian Legislative Assembly, 1998) highlights the perception that the exemptions granted could be justified by the power of the Minister to revoke these exemptions, should the need arise, by going to court. This argument is unlikely to be an effective deterrent for misapplication or misrepresentation if their reports are not available for external examination, as is the case for many religious organisations, whose disclosure requirements pertain only to members or the hierarchy of the affiliated church. Thus, the argument presented is that the lack of external reporting requirements for these organisations effectively renders any external monitoring largely ineffectual, and hence the power to revoke the exemption remains redundant for many of these charities.

An additional note on the questionable nature of these exemptions is the drafting of the current legislation. It seems somewhat controversial that the committee responsible for drafting the legislation in Victoria consisted of four representatives from the charitable community, three of whom were in fact religious welfare groups who were effectively exempted from many of the 
reporting requirements of the legislation. It seems ambiguous as to why these organisations were responsible for effecting legislation for the rest of the sector.

The size and number of these religious welfare groups is significant and has implications for trust throughout the non-profit welfare sector. Legislation regulating the sector and most particularly fund raising is supposedly enacted to protect donors and ensure minimum accountability levels for donations received from the general public. However, in light of preliminary statistics on giving in Australia (ABS, 1997), current legislation has largely exempted a subset of charities that effectively receive the largest proportion of all donations to nonprofits in Australia, that is, almost 40 per cent of all donations. Religious associations receive approximately twice the donations of the education and research sector, and close to ten times that received by environment and animal welfare groups. The Victorian Act states that 'The purpose [of the Act] ... is to regulate the raising and application of money and other benefits for noncommercial purposes from the public' (Victorian Legislative Assembly, 1998). It would seem that the purpose for which the various fund raising legislation were drafted and enacted has only partially been achieved.

\section{Explaining the Public Response}

The issue that now must be addressed is the contradiction that seems to be emerging. It would seem that religious welfare organisations have less legal requirements with respect to public reporting than many other non-denominational charitable groups. Nevertheless, they maintain substantial public support in terms of donations. Religious organisations generate more than double the amount of donations to any other category of non-profit association (ABS, 1997).

The argument could proceed that this type of association has more representatives than any other category of charity. However, given that there is no official database listing all Australian non-profits, and given that these organisations were well represented in the Industry Commission's Report of the top revenue generating welfare groups in Australia (Industry Commission, 1995), it is not necessary to presume that the disproportionate allocation of donations is a product of the proliferation of this form of charitable organisation. Thus, several plausible explanations may emerge to explain this phenomenon.

The first explanation presented is that donors are not concerned with reporting requirements, contrary to popular belief. In this explanation we may presume that revealed preference highlights that the imposition of relatively less external reporting requirements does not necessarily decrease donations. The second possible explanation is that religiously affiliated associations are considered more trustworthy not only by donors but also by policy makers. Thirdly, it may be hypothesised that policy makers are in fact sending signals to the public that they are more trustworthy than the rest of the non-profit nondenominational charitable community.

It is possible to attribute the latter two hypotheses to the age of these organisations. Given that a large majority of the first non-profit welfare groups in 
Australia had religious origins (Lyons, 1993) many of the older charities are likely to be religiously affiliated. The maturity of these organisations is likely to have a direct correlation with perceived trustworthiness. This argument seems to be supported by the results of the focus group surveys conducted for the benevolent Society of NSW (Consumer Contact, 1993). The survey found that the most significant factors in donors' perception of whether a charity was 'worthy' were the age (long established), and the reputation of the organisation, attributes most visibly attributable to religious charities in Australia. Beyond the advantages that maturity brings for public perception, many of these associations receive substantial funding not only from the government but also from foundations that demand the production of reports under funding agreements. Therefore there may be an inherent belief that funders, and most particularly the government, monitor these organisations indirectly through established contracts. Finally, acknowledgment must be given to the fact that religious organisations, though not required by legislation, may actually produce public reports in the first instance.

\section{Conclusion}

Though constitutional and fund raising legislation may not ensure broad ranging legislation to regulate the production of reporting, many organisations regardless of the method of incorporation are accountable in the production of reports, at minimum, to larger funding sources such as government, foundations or trusts or to voluntary umbrella associations. The issue that then must be raised is whether these reporting requirements are sufficient to discharge accountability for reporting to the general public and whether, beyond the surveys, the general public really cares.

The policy direction in this area is unlikely to change substantially. The introduction of more uniform Commonwealth legislation, and a single government authority to standardise and monitor the reporting process for charities would undeniably increase comparability and perhaps introduce more clarity to the reporting process and the sector as a whole. However, a similar recommendation was made in the report on Charitable Organisations in Australia (Industry Commission, 1995) and has not been adopted. Given current levels of donations, and the disproportionate allocation of these donations towards religious organisations, one may intuit that either the government or the public use a different barometer for trust-worthiness other than the production and dissemination of financial information. Thus, despite the existence of a blatantly uneven playing field with respect to the production of publicly available information by charitable organisations, any policy prescription to remedy this is likely to fall on deaf ears.

\section{References}

Australian Bureau of Statistics (ABS) (1997), Preliminary Survey on Giving, Australian Nonprofit Data Project. 
Campbell, B. (1998), 'Donors Want to Know Where the $\$ \$$ Goes', Fund Raising Management June:40-42.

Fitzgerald, E. (1997), Structuring and Restructuring Nonprofit Associations', Program on Nonprofit Corporations, Queensland University of Technology (Working Paper Series No. 71).

Huntly, C. (1996), 'A Century of Incorporated Associations in Western Australia: 18961996', School of Business Law, Curtin University (Working Paper Series, October).

Industry Commission (1995), Charitable Organisations in Australia, Report No. 45, AGPS, Canberra.

IOOF and ASSIRT (1997), 'Australians and Their Money : How Generous Are Australians?'

Lyons, M. (1993), 'The History of Non-profit Organisations in Australia as a Test of Some Recent Non-Profit History', Voluntas 4:301-325.

O'Keefe \& Partners (1998), 10th Annual Giving Trends in Australia Report.

Perrin, J. (1985), 'Differentiating Financial Accountability and Management in Governments, Public Services and Charities', Financial Accountability and Management $1(1): 11-32$.

Pocklington, J., M. Lyons, and J. Onyx, (1995), 'Data on Nonprofit Organisations: An Examination of Two Data Sources', Centre for Australian Community Organisations and Management, University of Technology Sydney (Working Paper Series No.30)

Victorian Legislative Assembly (1998), Fund Raising Appeals Act (No.78 of 1998).

Victorian Legislative Assembly (1998), Fund Raising Appeals Bill, Parliamentary Debates (Thursday 3 September).

I thank Rob Books, Sinclair Davidson, Myles McGregor Lowndes, the Editor and anonymous referees for the helpful comments received during the writing of this paper. I also thank the Pratt Foundation for its financial support of my research. 